\title{
Folklore y cultura de masas
}

En el año 1929 publicaron Petr Bogatyrev ${ }^{1}$ y Roman Jakobson ${ }^{2}$ en el Homenaje a Joseph Schrijnen su memorable y tan citado El folklore como forma específica de creación ${ }^{3}$. Partiendo de una crítica al realismo "naif" de los Junggrammatiker y su concepción de que sólo el lenguaje individual, el acto de lenguaje, era accesible al análisis, destacan, siguiendo a Saussure ${ }^{4}$, la oposición entre parole individual y langue comunitariamente aceptada, y plantean la pregunta de si y cómo los hechos de folklore conformados lingüísticamente de un individuo (por ejemplo, un cuentecillo contado en la tertulia de unas hilanderas) son tomados por la comunidad, socializados y, con ello, integrados en la langue. Su tesis principal decía entonces:

En el folklore perduran sólo aquellas formas que tienen carácter funcional para la comunidad dada. [...] Tan pronto [...] una forma queda sin función se extingue en el folklore, mientras que en una obra literaria conserva su existencia potencial ".

1 Para este folklorista y crítico literario ruso, cf. Kirill V. ČIsToV, “Petr Grigor evic Bogatyrev", Enzyklopädie des Märchens, 2 (1979), 575-578; Maria Di SAlvo, "Nota sull'autore / Bibliografia delle opere di P. G. Bogatyrëvn, Pëtr G. Bogatyrëv: Il teatro delle marionette, a cura di Maria Di Salvo et alii (Brescia: Grafo Edizioni, 1980), 129-154.

2 Para Jakobson, cf. la necrológica de Lyubomira PARPulova et alii en Journal of American Folklore, 97 (1984), 57-60 (con bibliografía complementaria). Cf. también Giovanni Battista BronzinI, "Il saggio di Bogatyrëv e Jakobson", en Cultura popolare. Dialettica e contestualità (Bari: Dedalo libri, 1980), 81-94.

3 P. Bogatyrev y R. JAKOBSON, "Die Folklore als eine besondere Form des Schaffens", Donum natalicium Schrijnen. Verzameling van opstellen door ondleerlingen en bevriende vakgenooten/...] (Nijmegen/Utrecht: Dekker \& Van de Vegt, 1929), 900-913. Versión española en R. JAKOBSON, Ensayos de poética (Madrid: Fondo de Cultura Económica, 1977), 7-22. Cf. Hermann BAUSINGER, Formen der "Volkspoesie (Berlin: E. Schmidt, 1980²), 47-50, 53, 55, 57; además, los provocadores argumentos de Jürgen KRAMER, "Sechs Thesen über "Foklore" und "Massenkunst", Zeitschrift für Volkskunde, 71 (1975), 21-27 (con un epílogo de Hermann Bausinger).

- Ferdinand DE SAUSSURE, Cours de lingüistique générale (Lausanne, 1916) (y eds. sucesivas). Versión española por Amado Alonso en Ed. Losada (Buenos Aires, 1945), y posteriores reimpresiones hasta hoy (ahora en Alianza Editorial, Madrid).

5 P. BOgatYrev y R. JaKobSON, op. cit., 902 (p. 10 en la versión española). 
El folklore necesita, desde luego, la memoria, el recuerdo ${ }^{6}$ para conservarse en la tradición; por el contrario, la literatura, fijada en el papel, puede caer en el olvido, pero más tarde ser rescatada de bibliotecas o archivos y de nuevo reactualizada. Una especie de "censura previa de la comunidad" ${ }^{7}$ decide si un hecho de folklore puede reproducirse o conservarse; si la creación poética oral tiene un carácter de "manada" ${ }^{8}$, la producción del folklore es, pues, en última instancia, un acto colectivo, una "producción por encargo", no como la literatura una "producción para el mercado". El folklore corresponde, por así decir, a una necesidad de la manada, muy ligada a la naturaleza; la literatura satisface la necesidad -creada externamente- de una masa ciudadana de lectores consumidores de cultura.

Tal delimitación del folklore podría defenderse aún hoy —sesenta y cinco años después- en Europa, aunque pudiera parecernos un poco alejada de lo científico: no sin cierto regusto de pesimismo cultural ${ }^{9}$, sobre todo - aun simplificándolo- en lo que se refiere al contexto social de las "comunidades de narración" ${ }^{10}$, así como en lo concerniente a las condiciones de recepción y producción de literatura popular y necesidades de los lectores ${ }^{11}$. En el mundo altamente industrializado de las grandes ciu-

6 Este elemento de la tradición, ya analizado en 1925 por Maurice Halbwachs (Les Cadres sociaux de la mémoire) apenas fue tenido en cuenta por Bogatyrev y Jakobson. Desde entonces a este procedimiento de la cultura del pueblo se le ha prestado mucha más atención. Cf. por ej.: Memoria del sacro e tradizione orale (Padua: Edizioni Messagero, 1984).

P. Bogatykev y R. JAKOBSON, op. cit., 903 (p. 11 en la versión española).

\& Ibíd., 906 (p. 15 en la versión española). G. B. BRonzini (op. cit., 88) traduce "Carattere collettivo" y borra con ello la metáfora zoológica, al igual que las versiones francesa y espanola.

9 Cf. Fritz STERn, The Politics of Cultural Despair (Berkeley, 1961). Versión alemana: Kulturpessimismus als politische Gefahr. Eine Analyse nationaler Ideologie in Deutschland (München: DTV, 1986).

1" Cf. por ejemplo Linda DÉGH, artículos "Erzählen", "Erzähler" en Enzyklopädie des Märchens, 4 (1984), 315-342, o el artículo anterior de DEGH, "Biologie des Erzählgutes", en Id., 2 (1979), 386-406; ahora también: R. SCHENDA, Von Mund zu Obr. Bausteine zu einer Kulturgeschichte volkstümlichen Erzählens in Europa (Göttingen: Vandenhoeck \& Ruprecht, 1993).

$"$ Rudolf SCHENDA, Volk obne Buch. Studien zur Sozialgeschichte der populären Lesestoffe, 1770-1910 (Frankfurt: Klostermann, 19883) (1. ${ }^{2}$ ed., 1970), passim. También la literatura es "producción por encargo": corresponde a lo que Robert Jauss ha denominado *horizonte de expectativas"; dicho de otro modo: sólo puede encontrar su finalidad en un "ámbito de expectativas" predeterminado. Cf. R. SCHENDA, "Sozialproblematischer Erwartungsraum und Autorenlenkung. Der Rezeptionsprozess des ideologiekonformen "populärem" Romans" (Eugène Sue: Les Mystères de Paris, 1842-43), Zeitschrift für Volkskunde, 72 (1976), 62-73. 
dades han cambiado enormemente no sólo las condiciones de producción y contenido del folklore ${ }^{12}$, sino que el mismo folklore ya no está en relación de tensión con la literatura, pues es también un componente de la producción de bienes culturales, especialmente en el ámbito de los medios de comunicación de masas. Vale decir, pues, que hay que reconsiderar el papel del folklore en nuestra sociedad moderna.

El concepto de folklore debería limitarse en lo posible a las manifestaciones orales pero también definirse más ampliamente, a poder ser sin la connotación de arte", como fue introducida en la discusión por William Bascom pero también por él relegada de nuevo a un segundo plano ${ }^{13}$. El folklore oral ya no tiene que ver sólo con la poesía, sino también con las expresiones corrientes de cada día; el saludo «Qué buen día hace hoy!n, pertenece al folklore aunque me parezca que carece de arte, y los maledicta $^{14}$ reivindican - aunque sea excepcionalmente- valor poético. Para conseguir una base común de trabajo quisiera definir provisionalmente el folklore como diversas clases de textos (géneros, especies) difundidos en el tiempo y/o en el espacio, orales y/o escritos (impresos), así como formas y fórmulas de lenguaje de uso cotidiano y generalizado ${ }^{15}$.

Bogatyrev y Jakobson habían dejado borrosas en su discusión las posibilidades de difusión del moderno mundo tecnificado; la vieja "comunidad rural, todavía sin alfabetizar, les servía como paradigma de sus reflexiones. Unos años más tarde, Walter Benjamin introdujo un nuevo concepto en la discusión, a saber: la posibilidad de reproducir técnicamente una obra de arte ${ }^{16}$, un concepto que puede ser muy útil también para nuestras reflexiones. La reproducción técnica de folklore existe, como muy tarde, desde la invención de la impresión de imágenes con planchas de

12 Ver Alan Dundes y Carl R. PAGTER, Work Hard and You Shall Be Rewarded. Urban Folklore from the Paperwork Empire (Bloomington/Indiana: Indiana University Press, 1978); Uli KUTTER, .Ich kündige!». Zeugnisse von Wünschen und Ängsten am Arbeitsplatz (Marburg: Jonas Verlag, 1982).

13 William BASCOM, "Verbal Art", Journal of American Folklore, 68 (1955), 245-252; Id., "Folklore, verbal art and culture", JAF, 86 (1973), 374-381; Id., artículo "Folklore", en Encyclopedia of the Social Sciences, 5 (1968), 496-500.

14 Maledicta. The International Journal of Verbal Agression, al cuidado de Reinhold Aman, Waukesha, Maledicta Press, desde 1977 (núm. 1) hasta 1988-89 (núm. 10, último número aparecido).

15 Cf. Hermann BAUSINGER, .Folklore, en Sowjetsystem und demokratische Gesellschaft. Eine vergleichende Enzyklopädie (Freiburg: Herder, 1969), 578-583; Carl STIEF, "Folklore" [in der USSR], en Id., 598-601; H. BAUSINGER, artículos "Folklore", “Folkloristik", en Enzyklopädie des Märcbens, 4 (1984), 1397-1403.

16 Walter BENJAMIN, Das Kunstwerk im Zeitalter seiner tecbnischen Reproduzierbarkeit [1936]. Drei Studien zur Kunstsoziologie (Frankfurt: Suhrkamp, 19682), 7-63. 
madera ${ }^{17} \mathrm{y}$, después, de textos con ayuda de tipos móviles ${ }^{18}$. Las percepciones sensoriales de los europeos se han ampliado más y más con la literatización y la iconización ${ }^{19}$ del pueblo desde el siglo XVI, los mundos de la experiencia de primera mano fueron complementados y parcialmente sustituidos por ámbitos de experiencia indirecta; así, podría hacerse, por ejemplo, una peregrinación a pie a Roma de una manera indirecta leyendo una guía de Roma con su texto y sus ilustraciones de los santos lugares. La singularidad, el aura de experiencia propia tal como se da en la comunicación folklórica de una comunidad rural, fue suplida y sustituida por la "repetibilidad" y la "fugacidad" 20 de la contemplación de una imagen narrativa impresa o de la lectura de un librito popular o de la lectura en voz alta de fragmentos de la Biblia o leyendas de santos ${ }^{21}$. La capacidad técnica de reproducir folklore facilita cada vez más su disponibilidad en el espacio y el tiempo; es, como impreso, una conserva percibida sensorialmente que se orienta al consumo en todo tiempo y en los más diversos lugares. También desde el siglo XV, por lo menos, el folklore sirve de aderezo para las más variadas sopas literarias: desde Ludovico Ariosto ${ }^{22}$, pasando por Rabelais ${ }^{23}$, hasta William Shakespeare ${ }^{24}$ encontramos docenas de elaboraciones folklóricas que, por su parte, han contribuido a su vez a la difusión literaria del folklore. Se puede continuar con los predicadores y los feriantes, gente más o menos formada literariamente que, en procesos

17 Las más antiguas imágenes de santos contienen ya en sus atributos (Santa Bárbara con la torre, etc.) elementos del folklore (motivo de la mujer encerrada, etc.). Cf., por ejemplo, la talla en madera de Christophorus en J. Mistler, F. Blaudez y A. JaCQuemin, Épinal et l'imagerie populaire (Paris: Hachette, 1961), 10.

18 Para las lecturas populares del tiempo de los incunables $\left(2 .^{a}\right.$ mitad del s. XV), cf. Rolf W. BREDNICH, Die Liedpublizistik im Flugblatt des 15. bis 17. Jabrbunderts, 1-2 (Baden-Baden: Koerner, 1975); Gisela ECKER, Einblattdrucke von den Anfängen bis 1555, 1-2 (Göppingen: Kümmerle, 1981); Rudolf JuCHHOFF, Kleine Schriften für Frühdruckforschung (edición al cuidado de Richard Mummendey) (Bonn: Bouvier, 1973).

19 R. SCHENDA, "Bilder vom Lesen - Lesen von Bildern", Internationales Archiv für Sozialgeschichte der deutschen Literatur, 12 (1987), 82-106.

20 W. Benjamin, op. cit., 18 y ss.

21 R. SCHENDA, "Vorlesen. Zwischen Analphabetentum und Bücherwissen. Soziale und kulturelle Aspekte einer semiliterarischen Kommunikationsform", Bertelsmann Briefe, 119 (Gütersloh, marzo, 1986), 5-14 (a dos columnas).

22 R. SCHENDA, "Ariosto, Ludovico", Enzyklopädie des Märchens, 1 (1977), 774-783.

23 René POMAu, "Rabelais et le folklore", Studi francesi, 7 (1963), 218-225.

${ }_{24}^{24}$ T. F. THISELtTon DYer. Folk-Lore of Shakespeare [1833] (New York: Dover, 1966); Charles G. SMITH, Shakespeare's Proverb Lore (Cambridge/Mass.: Harvard University Press, 1963); Kenneth Muir, "Folklore and Shakespeare", Folklore, 92 (1981), 231-240. 
semiliterarios ${ }^{25}$, presentaban a los analfabetos folklore de todo el mundo: mercancía folklórica extranjera, por así decirlo, antigüedades de los árabes, griegos y romanos por una parte, exotismo del área mediterránea por otra; en todo caso material no autóctono, no ya parole de la tertulia de hilanderas, sino langue de la literatura europea.

Posibilidad de reproducción y disponibilidad no impiden al todavía no alfabetizado espectador de hechos folklóricos introducirlos en su propia ejecución para proporcionar una nueva vida a este texto ya fijado. La tarea concreta de los reproductores de folklore (pongamos por caso una cantadora) es, como se sabe, éste ${ }^{26}$ : se apropia del texto con ayuda de su fiable memoria (adquisición), lo lleva a otro lugar (transposición y reproducción) y modifica, deliberada o inconscientemente, el texto aprendido (adaptación ${ }^{27}$ ) y en ese momento lo varía (variabilidad ${ }^{28}$ del texto) y/o contamina o combina con otros textos apropiados anteriormente (combinabilidad, fusionabilidad de los textos folklóricos ${ }^{29}$ ). La variabilidad de un texto, su maleabilidad asegura al mismo tiempo su constancia; formulado como una paradoja es así: un hecho folklórico es constante en la medida en que es variable. Formulado como metáfora: el hecho folklórico es un junco que se dobla pero no se rompe ${ }^{30}$.

Con los trabajos de historiadores y filólogos de los siglos XVIII ${ }^{31}$ (los anticuarios de la Ilustración) y XIX (sobre todo los consabidos románti$\cos ^{32}$ ) se reunió una ingente masa de hechos de folklore y se pusieron

25 R SCHENDA, "Volkserzählung und Sozialgeschichte", Il Confronto Letterario, 1 (Pavia, 1984), 265-278, especialmente 268.

26 Cf. Hermann STROBACH, Introducción a Deutsche Volksdichtung. Eine Einführung (Frankfurt: Röderberg, 1979), 5-28, espec. 6-19.

${ }_{27}$ Lauri HONko y Vilmos VOIGT (eds.), Adaptation, Change and Decline in Oral Literature (Helsinki: Suomalasien Kirjallisuuden Sera, 1981) (Studia Fennica, 26).

28 Annikki KaIVOLA-BREGENHøJ, "Variability and Narrative Context", en D'un conte... à l'autre. La variabilité dans la littérature orale (Paris: Editions du CNRS, 1990), 47-64.

29 Instructivos ejemplos ahora en Charlotte OBERFELD et alii, Brüder Grimm. Volkslieder. Aus der Handschriftensammlung der Universitätshibliothek Marburg, 1: Textband; 2: Kommentar (Marburg: N. G. Elwert, 1985, 1989), passim.

30 Jean DE LA FONTAINE, "Le chêne et le roseau", en Fables, I, 22 (numerosas ediciones).

31 Ver Richard M. DORSON, The British.Folklorists, 1: A History; 2-3: Peasant Customs and Savage Myths (London: Routledge \& Kegan Paul, 1968); Manfred GRÄTZ, Das Märchen in der deutschen Aufklärung. Von Feenmärchen zum Volksmärchen (Stuttgart: Metzler, 1988).

32 R. SCHENDA Y Hans TEN DOORNKAAT (eds.), Sagenerzäbler und Sagensammler der Schweiz. Studien zur Produktion volkstümlicher Geschichte und Geschichten vom 16. bis zum früben 19. Jabrbunder (Bern/Stuttgart: Haupt, 1988). 
a la venta cientos de libros ${ }^{33}$ y miles de textos sueltos (libros de lecturas escolares ${ }^{34}$, calendarios, revistas ilustradas). Con ello el folklore fue sacado de la esfera privada y del modo de producción oral y llevado al tráfico público del impreso y la lectura, con lo que no sólo se modifica la cantidad de textos y consumidores - de los veinte espectadores que visitaban una tertulia de hilanderas a los 20.000 lectores de una colección de cuentos- sino que también la calidad de ese texto y su uso han sufrido modificaciones esenciales: la traducción del dialecto a la lengua oficial, la traslación de la sintaxis oral a la escrita, el trasplante de formas específicas locales casi siempre rurales a otra área cultural casi siempre ciudadana y burguesa, el desplazamiento de expresiones concretas sobre la realidad material y social de cada día ${ }^{35}$, la metamorfosis de textos para adultos en historias para uso de escolares, la supresión de alusiones todavía comprensibles a todos en el ámbito aldeano, el sometimiento de la personalidad del narrador con su gesto y mímica, y así sucesivamente. Los cuentos de los hermanos Grimm o los de Ludwig Bechstein ${ }^{36}$ todavía

33 R SCHENDA, "Mären von deutschen Sagen. Bemerkungen zur Produktion von "Volkserzählungen" zwischen 1850 und 1870", Geschichte und Gesellschaft, 9 (1983), 26-48; Id., "Volkserzählung und nationale Identität. Deutsche Sagen im Vormärz (1830-48)», Fabula, 25 (1984), 296-303.

${ }^{34}$ Cf. por ejemplo: Liljana MARKs, "Usmena prica u skolskim udzbenicima" [La narración oral en los libros escolares], Narodna umjetnost, 24 (1987), 147-156; Ingrid TOMKOWIAK, "Traditionelle Erzählstoffe im Lesebuch. Ein Projekt zur schulischen Geschichtenpädagogik zwischen 1770 und 1920", Fabula, 30 (1989), 96-110; y también, Klaus ROTH, "Märchen als Lesestoff für alle; populäre Märchenbüchlein in Bulgarien", en Dona Etbnologica Monacensia. Leopold Kretzenbacher zum 70. Geburtstag. Edición de Helge Gerndt et alii (München: Institut für deutsche und vergleichende Volkskunde,
1983), 267-288.

35 Emst PHILlPPSON, Der Märchentypus von König Drosselbart (Greifswald, 1923) (FFC, 50), 39-48; Linda DEGH, "Grimm's "Household Tales" and its place in the household; the social relevance of a controversial classic, Michael M. METZGER y Katharina MOMMSEN (eds.), Fairy Tales as Ways of Knowing. Essays on Märchen in psychologv, society and literature (Bern: Lang, 1981), 21-53; R. SCHENDA, "Remarques sur le contenu socio-historique des récits legendaires", Le Monde Alpin et Rhodanien, 10 (1982), 185-188; Bengt HOLBEK, Interpretation of Fairy Tales. Danish Folklore in a European Perspective (Helsinki, 1987) (FFC, 239), 391; Luisa RUBINI, "Essen, soviel man mag, und leiden, was man muss": Die "Kinder- und Hausmärchen" der Brüder Grimm als Koch- und Hauswirtschaftsbuch,, en Die Küche, wie sie im Buche steht: Ausstellung im Wobnmuseum Bärengasse Zürich, 9 jun.-13 ago. 1989. Edición de Barbara E. Messerli Bolliger (Zürich: Präsidialabteilung der Stadt Zürich, 1989), 37-52.

36 Ruth BotTigheimer, "Ludwig Bechstein's Fairy Tales. Nineteenth Century Bestsellers and Bürgerlichkeit,, Internationales Archiv für Sozialgeschichte der
deutschen Literatur, 15/2 (1990), 55-88. 
muestran apenas un vislumbre de las funciones sociales y psico-sociales que estos textos habían tenido en su antigua esfera vital de la aldea y del artesanado de las ciudades. Asumen, como textos de lectura, nuevas tareas suplementarias: son portadores, por ejemplo, de enseñanzas de carácter histórico de la mitología supuestamente prehistórica y de la perdurable tradición nacional; muestran intenciones pedagógicas sobre el trasfondo de moral burguesa ${ }^{37}$; manifiestan una poética unicidad y homogeneidad del folklore ${ }^{38}$. Este folklore, sometido entre tanto a todos los fines ${ }^{39}$, disponible para todas las ideologías es, como una paysanne pervertie ${ }^{40}$, tirada en la ciudad y casi ya a punto de convertirse en una prostituta.

En el siglo XIX hay todavía una coexistencia pacífica entre las tradiciones folklóricas oral-campesina y literaria-ciudadana. Junto a ambos sistemas va creciendo más y más un tercer fenómeno, especialmente como consecuencia de la Primera Guerra Mundial. Tanto la sobreproducción de folklore y de su hermano el fakelore ${ }^{41}$, como también las principales creaciones espirituales de una sociedad cada vez más superindustrializada y superpolitizada, o sea, la superación de la catástrofe de la guerra, traen consigo un hastío del folklore, una "fatiga de tradición ${ }^{\star 42}$. El desplazamiento del pensamiento temporal, apreciable en toda

37 Ver Ruth BotTIGHeImer, Grimm's Bad Girls \& Bold Boys. The Moral E Social Vision of the Tales (New Haven/London: Yale University Press, 1987); Maria TATAR, The Hard Facts of the Grimm's Fairy Tales (Princeton/New Jersey: Princeton University Press, 1987); Jack ZIPES, The Brothers Grimm. From Enchanted Forests to the Modern World (New York/London: Routledge, Chapman and Hall, 1988).

38 Barbara KINDERMANN-BIERI, Heterogene Quellen - homogene Sagen. Philologische Studien zu den Grimmschen Prinzipien der Quellenbearbeitunguntersucht anband des Schweizer Anteils an den Deutschen Sagen (Basel: Schweizerische Gesellschaft für Volkskunde, 1989).

39 En la fiesta de los pastores de Unspunnen (Berna) en 1808 también "circularon poesías decentes. Se cantaron algunas estrofas compuestas por la conocida Emilia von Harmes (señora von Berlepsch), así como algún otro cantar referente a la historia del lugar y a la finalidad de la fiesta (...). Una balada tuvo como tema la historia de una señorita de Unspunnen: "Ida, la hija de Burkhard de Unspunnen" (...). Johan Jakob HOTTINGER y Gustav SCHWAB (eds.), Die Schweiz in ibren Ritterburgen und Burgscblössern, 3 (Bern/Chur: Leipzig, 1839), 220.

40 Cf. la novela del mismo nombre de Nicolas Edme Restif de la Bretonne (1784), continuación de su Paysan perverti de 1776.

41 Ver Richard M. DORSON, ‘Fakelore", Zeitschrift für Volkskunde, 65 (1969), 56-64; Dave HARKER, Fakesong - The Manufacturing of British "Folksong", 1700 to the Present Day (Milton Keynes: Open University Press, 1985).

42 R SCHENDA, .Das Onophrius-Fest in Sizilien", Österreiche Zeitscbrift für Volkskunde, 68 (1965), 151-167, espec. 164. 
Europa, continúa ${ }^{43}$. El folklore establecido al modo épico a partir del sistema temporal cíclico del año (invierno, etc.) y del día (noche, etc.) es comprimido en el sistema temporal lineal y por ello condensado bajo la presión de la nueva economía del tiempo. Desde 1920 existe algo así como un "basic folklore " ${ }^{44}$, un catálogo de slogans, comprimido aunque todavía sin imprimir, del folklore de los siglos XVIII y XIX conocido por todos. La abreviación de actos de comunicación de todas clases produce formas encogidas, "grados de atrofia" 45 , por ejemplo la facecia abreviada para chiste y el chiste "apresado" de nuevo ${ }^{46}$. En el almanaque Bruder-Clausen Kalender auf das Jahr 1923 (Sarnen, Suiza) aparece en 1922 "un cuento moderno" con el título Un regalo del hada. El hada se llama "Persila", el regalo encantado, "Persil"; este moderno cuento de detergentes sólo dura medio minuto. En 1918 se imprimieron en Berna los nuevos billetes de cien francos suizos, en los que figuraba la efigie de Guillermo Tell con su ballesta ${ }^{47}$. En este caso a Tell no le hace falta hablar; el significado de ese evidente signo quiere decir: Liberación (de la amenaza de la guerra), Fuerza (de Suiza), Estabilidad del franco. Los creadores de este nuevo folklore de mass-media se basan en la familiaridad del público desde hace por lo menos cien años con el mensaje de texto largo ${ }^{48}$ comprimido y lo

"3 Ver Edward P. ThOMPSON, "Time, Work-Discipline and Industrial Capitalism", Past and Present, 38 (1967); 56-97; Rudolf WENDORFF, Zeit und Kultur. Geschichte des Zeitbewusstseins in Europa (Opladen: Westdeutscher Verlag, 1980); Ursula y HeinzAlbert Heindrichs (eds.), Die Zeit im Märchen (Kassel: Röth, 1989).

44 Tomo la denominación de Ekhardt FraHM, "Zum Medien-Foklorismus", en Direkte Kommunikation und Massenkommunikation (Tübigen: Tübinger Vereiningung für Volkskunde, 1976), 105-126, espec. 115.

t5 Ver Kurt Ranke, "Schwank und Witz als Schwundstufe", Die Welt der Einfachen Formen (Berlin/New York: De Gruyter, 1955), 61-78; Norbert NeumanN, Vom Schwank zum Witz. Zum Wandel der Pointe seit dem 16. Jabrbundert (Frankfurt/New York: Campus, 1986).

th Hannjost Lixfeld (ed.), Arbeitstexte für den Unterricht. Witz (Stuttgart: Reclam, 1986), 50 y ss.

• Uli WINDIsch y Florence CORNU, Tell im Alltag (Zürich: Edition M, 1988), 160.

*7 En Art, en el suizo cantón de Schwyz, en 1784 se celebró un desfile con todas las grandes figuras de esta saga helvética: detrás de una compañía de cazadores, con flechas en el sombrero y ballestas en la mano, marchaban Guillermo Tell y su hijo, los tres libertadores Stauffacher, Melchtal y Fürst, así como Conrad Baumgarten, «qui, d'un coup de hache, fendit la tête d'un noble de Wolfenchies [sic], prêt à faire à sa femme et à lui, l'outrage le plus sanglant [!]; luego seguían los compañeros de Gessler, y así sucesivamente. Al final de la fiesta se representó en el teatro un drama en cinco actos sobre Tell, y lo mismo se repitió en los dos días siguientes. Cf. Le Conservateur Suisse, 1 (Lausanne, 1813), 276-287, espec. 277. El autor del artículo era probablemente el "Doyen. Phillipe Sirice Bridel. 
envían como una señal abreviada. Estenograma e iconograma bastan para despertar miles de deseos ${ }^{49}$. El miedo a lo desconocido se conjura tan pronto la nueva mercancía se introduce en las vestiduras del folklore, viejas conocidas ${ }^{50}$.

Por eso si avanzáramos a grandes saltos hasta la realidad actual de la cultura de masas, no deberíamos caer en la falsa apreciación de que, como todo el mundo moderno está ya lleno de restos de folklore, sólo necesitamos abrir un periódico para tropezarnos de nuevo con una Caperucita roja ${ }^{51}$ o un Rey de las ranas ${ }^{52}$. Seguramente es cierto que los concentrados de folklore surgen en muchos sitios de nuestra cotidianeidad industrial, especialmente en la publicidad ${ }^{53}$, en los libros escolares y otras lecturas populares, sobre todo en la literatura patriótica, en el cine ${ }^{54}$, en guías turísticas y revistas ilustradas ${ }^{55}$. La industria cultural ${ }^{56}$ utiliza estos materiales muy conocidos junto con una serie de señales que provocan, desde luego, un alto nivel de atención. Menciono simplemente los temas automóvil,

49 Cf. Roland BARTHES, Mythes (Paris, 1957); Nicholas WADE, Visual Allusions. Pictures of Perception (Hove/Eas Sussex: Lawrence Erlbaum, 1990).

50 Eugen LeITHERER y Hans WiCHMANn, Reiz und Hülle. Gestaltete Warenverpackungen des 19. und 20. Jabrbunderts, 24* (Basel: Birkhäuser, 1987).

51 Ver Jack ZIPES, The Trials and Tribulations of Little Red Riding Hood. Versions of the Tale in Sociocultural Context (South Hadley: Bergin \& Garvey, 1984²); Alan Dundes (ed.), Little Red Riding Hood. A Casebook (Madison/London: The University of Wisconsin Press, 1989).

52 Lutz RÖHRICH, Wage es, den Frosch zu küssen! Das Grimmsche Märchen Nummer Eins in seinen Wandlungen (Köln: Diederichs, 1987).

53 Wolfgang MIEDER, Das Sprichwort in unserer Zeit (Frauenfeld: Huber, 1975).

54 Especialmente las películas basadas en cuentos han sido objeto de una amplia consideración. Cf. Tom DAvENPORT, "Some Personal Notes on Adapting Folk-Fairy Tales to Film", Children's Literature, 9 (1981), 107-115; Donald HAASE, "Gold into Straw: Fairytale movies for children and the culture industry", The Lion and the Unicorn, 12 (1988), 193-207.

55 Maja BoŠKović-STULLI, "Múndliche Dichtung ausserhalb ihres ursprünglichen Kontextes", Folklore and Oral Communication = Narodna umjetnost, 18 (1981), 37-52; R. SCHENDA, "Märchen erzählen - Märchen verbreiten. Wandel in den Mitteilungsformen einer populären Gattung”, en Klaus DODERER (ed.), Über Märchen für Kinder von heute (Weinheim/Basel: Beltz, 1983), 25-43 (versión inglesa en Ruth B. BotrigheImer (ed.), Fairy Tales and Society: Illusion, Allusion and Paradigm, Philadelphia: University of Pennsylvania Press, 1986, 74-94). Para todo el conjunto $\mathrm{cf}$. el volumen recopilatorio de Jörg UTHER (ed.), Märchen in unserer Zeit. Zu Erscheinungsformen eines populären Erzäblgenres (München: Diederichs, 1990).

56 Michael KausCH, Kulturindustrie und Populärkultur. Kritische Theorie der Massenmedien (Frankfurt: Fischer TB Verlag, 1988). 
cerveza, naturaleza, viajes, sexualidad, deporte o incluso magia ${ }^{57}$ o Edad Media ${ }^{58}$. La acumulación de estas señales tan actuales sobre elementos del "basic folklore” actúa primero sorprendiendo y luego persuadiendo. La omnipresente señal cerveza alcanza, por decirlo así, un alto contenido alcohólico si se combina con algo como bada o caballero o también con la denominación genérica cuento o con expresiones que gustan. Un anuncio turístico de los ferrocarriles suizos decía en invierno de 1989-90: „Un invierno como un cuento. Legendario valle de los valles" ${ }^{59}$. El viaje que se ofrece al mercado, junto con cuento y leyenda, no sólo se califica más alto sino que al mismo tiempo la mercancía contiene expreso el signo de calidad Shakespeare y aún se revaloriza con una fórmula retórica que evoca el Libro de los libros. Un reclamo de cerveza sin alcohol muestra un vaso de cerveza vacío y otro lleno, y dice: "Mass leer [= jarra de cerveza vacía] / Massvoll [ = moderado]. Die Mass aller Dinge [= la medida de todas las cosas]" "n. Aquí se nos remite ante todo a un reclamo de cerveza más antiguo que se refería a la reiterada alusión al folklore shakespeariano "medida a medida" (es decir: vaso a vaso una excelente cerveza). El juego de palabras aún sigue funcionando aquí: "Mass voll" quiere decir: vaso de litro lleno de cerveza, "massvolln: usted puede beber y permanecer sobrio; "die Mass aller Dinge», finalmente, juega con la cita de Protágoras el bombre es la medida de todas las cosas; esa cerveza se atribuye un valor de verdad realmente clásico-filosófico a través de esta acumulación de señales.

Simples alusiones de un charcutero a Mesita, cúbrete, de una tienda de telas a El vestido nuevo del emperador, de un pastelero a Hänsel y Gretel no bastan ya para una publicidad moderna y sofisticada. Para producir la "Corporate identity" 61 de una mercancía se necesita algo más que un trozo de papel de envolver. El folklore es sólo un elemento aprovechable en esas campañas publicitarias de los medios de comunicación, más utilizable

57 Linda DÉGH, "Magie als Versandartikel", en Utz JEGGLE et alii (eds.), Volkskultur in der Moderne. Probleme und Perspektiven empirischer Kulturforschung (Homenaje a Hermann Bausinger) (Reinbek: Rowohlts Enzyklopädie 431, 1986), 290-307.

s. Sergio GENSINI, Introduzione al convegno. Il sogno del Medioevo. Il revival del Medioeto nelle culture contemporanee. Relazioni e communicazioni del convegno di San Gimignano 11-12 novembre 1983 (Quaderni medievali, 21) (Bari: Edizioni Dedalo, 1986), 11-17.

59 Ver el folleto titulado, "Mehr erleben mit der Bahn*, núm. 4, Bern, Schweizerische Bundesbahnen, Werbedienst, November, 1989.

n TV plus. Programa de radio y televisión del 7 al 13 de abril de 1990 (Suplemento del diario de Zürich Tages-Anzeiger, p. 2). El juego de palabras (leer = "vacio", voll = "lleno" y Mass = "medida"), evidente para un germanohablante, pierde su virtualidad al traducirse al castellano.

61 E. Leitherer y H. WichmanN, op. cit., 244-247. 
cuanto más conocido, casi se podría decir cuanto más consumido sea. Lo archiconocido, combinado con otras señales polivalentes, aparece a una nueva y sorprendente luz ${ }^{62}$; quien reconozca esta interrelación, experimenta una nueva vivencia del "ya caigo", que no es desemejante a la comprensión de un chiste ${ }^{63}$.

Reproducido y situado en una interrelación nueva, el folklore por su parte produce nuevos géneros de folklore. Que los mismos medios de comunicación contribuyen a la conservación y creación del folklore se ha hecho ya evidente, especialmente en el sector de la transmisión de canciones ${ }^{64}$, en la ampliación de los cuentos de miedo ${ }^{65}$ y en los modismos. Mensajes perennes, impresos o emitidos por radio, actúan de igual manera conservando y creando folklore. El folklore infantil retoma siempre nuevos elementos del lenguaje de la publicidad y de los programas de la televisión ${ }^{66}$, ya repitiéndolos en cuentos y juegos, ya - de modo más distanciado- como parodia de lo visto u oído ${ }^{67}$. No es necesario interpretar aquí detalladamente estos fenómenos. Cada uno los tiene cada noche ante los ojos en la televisión y cada mañana en el oído en el tren, en el colegio o en la oficina. Los titulares de los periódicos reproducen diariamente su propio tipo de folklore.

Más importante me parece aducir otra limitación de la omnipresencia del folklore en la cultura de masas: hay un espectro nada estrecho de

62 La sorpresa puede ampliarse al shock o a la indignación cuando en la publicidad se hiere el pudor o los sentimientos religiosos, como en la comercialización de la Santa cena de Leonardo da Vinci o la Creación de Miguel Angel. Cf. Michelangelo wirbt für Fassadenisolation* [= M. A. hace propaganda de aislamiento de fachadas], Neue Zürcher Zeitung, 29-9-1989, p. 55.

63 Un ejemplo de la Suiza francesa: el cartel de la compañía aérea nacional (1990) que dice: «Genève - Los Angeles non stop. Jamais le mardi. Jamais le vendredi. Et alors? Demandez à votre agence de voyages ou à Swissair.

64 Johannes MOSER, "Ansätze zu einer neuen Volksliedforschung", Jabrbuch für Volksliedforscbung, 34 (1989), 56-69, espec. 64-67.

65 Bengt af KLINTBERG, Rättan i pizzan. Folksägner $i$ vàr tid (Stockholm: Norstedt, 198833). (Versión alemana: Die Ratte in der Pizza und andere moderne Sagen und Grosstadtmythen, Kiel; W. Butt Verlag, 1990).

66 Para la discusión actual (1989-90) sobre los vídeos de terror, cf. Angela RIESBERG y Ursula MARTIN-NEW, Macbo-, Monster-, Medienfreizeit. TV-Videokonsum Jugendlicber (Pfaffenweiler: Centaurus, 1988) (Medienwissenschaft, 4). Cf. ahora R. SCHENDA, "Der Computer, das Volk und der neue Analphabetismus", en Der industrialisierte Mensch. [Actas del] 28. Deutscher Volkskunde- Kongress. Hagen, 7 bis 11 Oktober 1991 (Münster: Ardey, 1993), 441-457.

67 Alfred MESSERL, Elemente einer Pragmatik des Kinderreimes aufgrund autobiographischer Texte und einer Befragung von Zürcher Scbulkindern im Jabr 1985 (Tesis doctoral, Zürich, 1989) (Aarau, 1991). 
géneros folklóricos que resultan inapropiados para su aprovechamiento en los medios de comunicación. Se trata de géneros de pequeño alcance pero de amplia significación psico-social: es, ante todo, el intercambio de informaciones locales sobre personas, sucesos y problemas de la vida cotidiana, una forma narrativa de comunicación, mal traducida bajo el concepto de Klatsch ${ }^{68}$ (chismes, gossip, comérage). Klatsch es small talk, pequeño chismorreo de éste y aquél (el latín quamquam dio el francés cancan), pero es la infalible argamasa con la que el bomo communicator se pega a los demás. Klatsch es sólo utilizable de manera paródica en la comunicación de masas (como han hecho, p. e., en Alemania, Hans D. Hübsch o Jürgen von Manger; en Suiza, Emil; en Francia, Coluche); con todo, estas parodias tienen mero valor de entretenimiento, no las funciones psico-sociales de asegurar la cohesión y la pertenencia. Precisamente estas funciones las asume también otro género del folklore: el saludo personal, individual, que se refiere al quehacer de los demás: "Vaya, ¿paseando también?" o "¿Ya está mejor su hija?" "69. También estas son locuciones formalizadas y ritualizadas, pero son empáticas, se refieren a personas y situaciones y no son generalizables como "iHola!" o "Ciao!", saludos universales en los medios de comunicación de masas. Y en este contexto yo quisiera mencionar un tercer género, que habrá de quedar como parole porque no le está permitido avanzar hacia la langue de la cultura de masas: la maldición y el insulto, el intercambio de injurias y la expresión de la indignación espontánea ${ }^{70}$. Desde luego, el folklore en su conjunto todavía no ha sido víctima de la explotación y la manipulación ${ }^{71}$ de la industria de la cultura.

Con esta metáfora "ser víctima" la discusión se encamina, sin embargo, por el peligroso rumbo de la crítica pesimista de la cultura. Pero no hay

(n) Ver Max GluckmanN, "Gossip and Scandal", Current Antrbopology, 4 (1963), $307-$ 316; Anders Gustavsson, "Folklore in Community Conflictis. Gossip in a Fishing Community", Art. Scandinavian Yearbook of Folklore, 35 (1979), 49-85; Jörg. R. BERGMANN, Klatsch. Zur Sozialform der diskreten Indiskretion (Berlin/New York: De Gruyter, 1987); Angela KEPPLER, "Der Verlauf von Klatschgesprächen", Zeitschrift für Soziologie, 16 (1987), 288-302.

69 Anna ZOLLINGER-ESCHER, Die Grussformeln der deutschen Schweiz (Tesis doctoral, Freiburg/Br., 1925); Hermann BAusinger, artículos "Gruss", "Grüssen", Enzyklopädie des Märchens, 6 (1990), 274-276.

7) Sabine KIENITZ, "Da war die Weibsperson nun eine der Ärgsten mit Schreien und Lärmen", Der Stuttgarter Brotkrauall (1847), en Carola LipP (ed.). Schimpfende Weiber und patriotische Jungfrauen Frauen im Vormärz und in der Revolution 1848/49 (Moos/Baden-Baden: Elster Verlag, 1986), 76-87.

-1 Amold NIEDERER, "Le folklore manipulé, Schweizerisches Archiv für Vokskunde, 79 (1983), 175-186. 
motivo para lamentarse: nunca ha ido el folklore mejor que bajo la bandera de la cultura de masas, nunca ha alcanzado mayor asentimiento, desde hace tiempo ha sido admitido -desde la parole- no sólo en la langue, sino introducido incluso en un ámbito del que Bogatyrev y Jakobson aún no habían tenido conocimiento: en un discurso ${ }^{72}$ que representa una "mezcla comunicativa" ${ }^{73} \mathrm{y}$, al mismo tiempo, está ligado con las acciones e intenciones más dispares; con estrategias de ventas del mercado orientado hacia el capitalismo ${ }^{74}$, con maniobras de contacto psico-higiénicas (por ejemplo en relación con la creciente destrucción de nuestro medio ambiente), con las correspondientes remisiones al supuesto Buen Tiempo Pasado ${ }^{75}$, con tácticas electorales políticas de toda ralea ${ }^{7}$. La complaciente aceptación del folklore, que favorece la generalizada tendencia a la nostalgia ${ }^{7}$, no debe engañarnos sobre el hecho de que, con esa máscara de inocencia, puede camuflarse una serie de ideologías que en modo alguno son tan inocentes. Seguir la pista de tales movimientos de máscaras me parece que es la urgente tarea de la investigación folklórica de hoy.

Folklore: ¿una forma específica de creación? La vieja pregunta, antes como después, tiene su justificación. Sólo necesita, sesenta y cinco años más tarde en un mundo radicalmente transformado, toda una serie de nuevas respuestas. El debate sobre el folklore no está aún cerrado en

72 Neil Postman, Amusing Ourselves to Death. Public Discourse in the Age of Show Business (1985) (New York/London: Penguin Books, $1987^{3}$ ).

73 R. SCHENDA y H. ten DOORNKAAT, op. cit., 17 (ver nota 32).

74 Hermann STROBACH, "Folklore-Folklorepflege-Folklorismus", Jabrbucb für Volkskunde und Kulturgescbichte, 10 (1982), 9-52, espec. 33 y ss.

75 Para la exposición de las ideas del filósofo zuriqués Hermann Lübbe sobre este tema, ver Peter Assion, "Historismus. Traditionalismus. Folklorismus. Zur musealisierenden Tendenz der Gegenwartskultur", en U. JEGGLE et alii, op. cit., $351-362$ (ver nota 57).

76 A. Niederer, op. cit., 177-180. Un análisis de los discursos de política interior (1989/90) del canciller alemán Helmut Kohl sería muy instructivo a este respecto ("en este país nuestron, "la corriente alemana de la historia", "momento históricon, etc.). Un análisis periodístico de las expresiones "castizas" del presidente francés François Mitterrand se halla en el periódico Libération del 8 de abril de 1990, p. 5: "Le Président se ressource dans le terroir*. Ahora cf. también Ernst LEISI, "Churchills Beschwörungsformeln. Zum Stil einer Rede vom Sommer 1940", Neue Zürcher Zeitung de 19/20 de mayo de 1990 , p. 70.

77 Volker FISCHER, Nostalgie: Geschichte und Kultur als Trödelmarkt (Luzern: Bucher, 1980); Béatrice BRUNNER y Martin HEULE, .Der Zürcher Flohmarkt - ein Stück verordneter Nostalgie?*, Scbweizerisches Archiv für Volkskunde, 82 (1986), 4-21. 
absoluto. En los años 2000, totalmente dominados por la electrónica, también habrá de actualizarse de acuerdo con las circunstancias ${ }^{78}$.

\author{
RUDOLF SCHENDA \\ Volkundliches Seminar \\ Universität Zürich
}

Partiendo del concepto de folklore acunado en 1929 por Bogatyrev y Jakobson y aún válido, se propone una revisión y actualización del mismo a la vista de las nuevas circunstancias de su uso. La reproducción técnica de los hechos folklóricos y su disponibilidad en el espacio y el tiempo hicieron posible durante los siglos XVIII y XIX su difusión y consumo masivos y una profunda modificación de sus funciones anteriores. Ya en nuestro siglo, los medios de comunicación -importantes creadores y conservadores de folklore- lo utilizan, condensado en slogans y asociado a otros mensajes, para fines muy diversos y no siempre inocentes.

Following the concept of folklore conceived by Bogatyrev and Jakobson in 1929, still valid today, we suggest revising and updating it, considering its new usage. The technical reproduction of folk events and its availability in space and time became more widespread and popular among the people, during the XVIII and XIX centuries, and it also underwent a great transformation of its previous functions. In our century, the mass media is an important creator and maintainer of folklore, and they use it slogans, associated with other messages, not allways connected with basic folklore.

78 Traducción del alemán de Domingo Blanco. I. B. „República do Uruguai. Vigo. 